\title{
DETERMINACIÓN DE AFLATOXINAS EN ALGUNOS PRODUCTOS NATURALES UTILIZANDO EL MEDIO AGAR COCO Y ELISA LIGADA
}

\author{
Br. Mariano Freddy Medina Gutiérrez, José Irey Namijira y Mirtha Roque Alcarraz \\ Instituto de Investigación en Química Biológica, Microbiológica y Biotecnología \\ "Marco Antonio Garrido Malo"
}

\begin{abstract}
Identificación, determinación y cuantificación de aflatoxinas producidas por hongos aflatoxigenicos en productos naturales, como alimentos naturales y medicamentos de origen vegetal. Utilizando el medio Agar Coco Oxitetraciclina (CAMO) donde se aprecia fluorescencia azul $\mathrm{cn}$ cl UV para determinar y cuantificar la aflatoxina se uso Elisa ligada, utilizando el fotocolorimetro EIH Neogen y el programa Logit donde los resultados se dan en $\mathrm{ppb}$ o ug/kg de aflatoxina.
\end{abstract}

Palabras clave: Aflatoxinas, Agar Coconut Oxitetraciclina, Elisa.

Hace mucho se ha observado que la presencia de hongos puede ocasionar cambios en textura, color, sabor y calidad de los alimentos. En nuestro país es considerable el consumo de productos naturales como: alimentos naturales o medicamentos de origen vegetal. Estos se elaboran y se expenden sin el control sanitario que requieren estos productos; siendo la presencia de aflatoxinas un riesgo para su salud.

En tal sentido se justifica el presente trabajo para demostrar la existencia de aflatoxina en productos naturales y asimismo estudiar un método rápido y sensible para la determinación de ellas.

\section{Materiales y Métodos}

\section{Materiales, Reactivos y Equipos}

Reactivos Químicos

- Etanol al 70\%

- Metanol al 70\%

- Oxitetraciclina $250 \mathrm{mg}$ PFIZER

Medios de Cultivo

- Agua Peptonada

- Agar Sabouraud DIFCO

- Agar Coco Oxitetraciclina (CAMO)

- Agar Czapeck extracto de levadura.

Materiales de Laboratorio

- Placas Petri

- Placas Petri descartables

- Tubos de vidrio de $10 \mathrm{~cm}$

- Pipetas de $25 \mathrm{~mL}, 10 \mathrm{~mL}$ y $1 \mathrm{~mL}$.

- Espátulas de Driglaski

- Viales

- Bolsas estériles de $15 \times 30$

- Laminas porta y cubre objetos

- Papel Whatman N'1

- Papel toalla

- Micropipeta de $100 \mathrm{uL}$

- Micropipcta multicanal de $100 \mathrm{uL}$

- Tips descartables
- Timer

- Papel indicador MERCK

Equipos

- Microscopio simple

- Lámpara UV

- Equipo de Karl Fisher

- Kit Cuantitativo de ELISA para aflatoxinas VERATOX

- Lector EIA para ELISA

- Programa Logit versión 1.04

\section{Análisis de las Muestras}

Para el desarrollo de la presente investigación se utilizaron diversos métodos de análisis, con la siguiente secuencia:

- Toma de muestras.

- Determinación de pH y humedad de las muestras.

- Recuento de hongos totales en Agar Sabouraud Oxitetraciclina (ASO) y en Agar Coco Oxitetraciclina (CAMO).

- Recuento de hongos aflatoxigenicos en CAMO.

- Análisis de hongos aflatoxigenicos en CAMO con inductores para 
aumentar la producción de aflatoxinas.

- Identificación de hongos aflatoxigénicos.

- Análisis cualitativo y cuantitativo de aflatoxinas usando ELISA compctitiva.

\section{Toma de muestras}

Las muestras en número de 50 fueron tomadas al azar entre los diferentes establecimientos de venta de productos naturales del centro de Lima. Para mejorar el análisis estadístico se dividieron en dos grupos.

\begin{tabular}{cc}
\hline \multicolumn{2}{l}{ Tabla 1: Muestras Analizadas en la Investigación } \\
\hline Cantidad & \multicolumn{1}{c}{ Productos } \\
\hline 26 & Suplementos Alimentarios \\
24 & Medicamentos Vegetales \\
\hline
\end{tabular}

\section{Determinación del pH y Irumedad de las Muestras}

Para determinar la humedad se tomo $1 \mathrm{~g}$ de muestra, se mcz.cló con agua destilada con agitación constante durante 3 a 5 minutos, se decantó y al líquido decantado se midió su $\mathrm{pH}$ con papel indicador MERCK.

Para determinar la humedad se tomó 3 a $5 \mathrm{~g}$ de muestra y se usó el equipo de Karl Fisher (determina la cantidad total de agua en las muestras).

\section{Dilución de las muestras}

En una bolsa estéril $(15 \times 30)$ se tomo 10 g de muestra molida, se agrego $90 \mathrm{~mL}$ de Agua Peptonada (AP), agito durante 2 a 3 minutos, obteniendo de esta manera la dilución $10^{-1}$ o $1 / 10$, se dejo a temperatura ambiente por 1 a 2 horas para revificar y dispersar a los microorganismos. Posteriormente se realizaron diluciones, transfiriendo 1 $\mathrm{mL}$ de la dilución $10^{-1}$ a $9 \mathrm{~mL}$ de AP hasta completar de la misma forma la dilución $10^{-3}$.

Recuento de hongos totales y hongos aflatoxigénicos

De las diluciones realizadas, se transfirieron $0,1 \mathrm{~mL}$ a las placas con
Agar Sabouraud Oxitetraciclina (ASO) y Agar Coco Oxitetraciclina (CAMO), se disperso homogéncamente con ayuda de la espátula de vidrio Driglaski, por cada siembra se esterilizo la espátula con etanol al $70 \%$ y flameándola en el mechero. Las placas se incubaron a $25^{\circ} \mathrm{C}$ por 5 a 6 días en forma invertida.

El recuento de hongos totales se realizo en las placas con ASO y CAMO. El recuento de hongos aflatoxigenicos se realizo en las placas con CAMO, colocándolos bajo la luz UV para observar la fluorescencia azul alrededor de las colonias (característica de 1 as aflatoxinas). El recuento de hongos totales $y$ aflatoxigénicos se realizo tomando las placas que contenían entre 10 a 150 unidades formadoras de colonia. Las colonias con fluorescencia se aislaron en viales conteniendo Agar Sabouraud para su posterior identificación.

\section{Hongos aflatoxigénicos en CAMO con inductores para aumentar la producción de aflatoxinas}

Las muestras aisladas en viales se sembraron en CAMO con diferentes inductores para estimular la producción de aflatoxinas, se incubaron a $25^{\circ} \mathrm{C}$ por 3 a 4 días. Los diferentes medios de cultivo utilizados fueron los siguientes:

- CAMO sin inductores.

- CAMO mas 0,5 g de Zn en 1000 $\mathrm{mL}$ de medio (ion metálico que estimula la producción de aflatoxinas).

CAMO mas $63 \mathrm{mg}$ de sacarosa en $1000 \mathrm{~mL}$ de medio (carbohidrato que estimula la producción de aflatoxinas).

CAMO mas $63 \mathrm{mg}$ de extracto de levadura en $1000 \mathrm{~mL}$ de medio (fuente de nitrógeno que estimula la producción de aflatoxinas).

- CAMO mas los tres inductores. 


\section{Identificación de Hongos Aflatoxigenicos}

a) Utilizando Microcultivos.- Para la identificación de los hongos se usaron microcultivos, estos se incubaron a $25^{\circ} \mathrm{C}$ por tres días y se observaron en un microscopio simple a mediano aumento.

b) Cultivo en Agar Czapeck Extracto de Levadura CYA.- Este medio de cultivo se incubo a dos temperaturas: $25^{\circ} \mathrm{C}$ y $37^{\circ} \mathrm{C}$ y se leyeron después de siete días, esto se uso solo para identificar a las cspecies del genero Aspergillus, para este fin se usaron claves que se deben seguir desde el principio porque son descartables (Pitt, 1996).

\section{Análisis Cualitativo y Cuantitativo de Aflatoxinas}

\section{Características de la Prueba de ELISA}

La prueba de ELISA usualmente emplea un anticuerpo inmovilizado en un soporte sólido y el ligando esta marcado a una enzima; la fosfatasa y la peroxidasa del rabano son enzimas económicas y están disponibles comercialmente en forma muy purificada, cstas pueden emplear sustratos cromógenos o fluorogenos, dando una señal de absorbancia o fluorescencia, respectivamente.

La ventaja de un substrato cromogenico es que sus productos pucden detectarse visualmente, los productos fluorescentes pueden detectarse a concentraciones 100 a 1000 veces menores de los cromógenos. Numerosas son las variaciones ideadas para la prueba de ELISA, algunas están basadas en reacciones competitivas mientras que otras son ensayos "sándwich" directos.

\section{Principios de la prueba de ELISA VERATOX}

Las aflatoxinas están conjugadas a una cnzima peroxidasa de rábano, esta es usada como un antigeno conocido (conjugado). En unas celdillas se mezclan nuestras supuestas aflatoxinas (extraídas por solventes) y las cnzimas conjugados. Posteriormente esta mezcla a unas celdillas de plásticos en donde compiten por los anticuerpos específicos a las aflatoxinas adheridos a la superficie de la parcd interior de las celdillas; los excesos de aflatoxinas y cnzimas - conjugados no fijados al anticuerpo son desechados.

La enzima sustrato, adicionada a cada celdilla, es catalizada por la enzima fijadora y cambia de color, la intensidad de color depende de la cantidad de enzima, conjugado fijados a los anticucrpos de color oscuro indica menor presencia de aflatoxinas en las muestras(aflatoxinas libres), mientras el color claro indican mayor presencia de aflatoxinas. Después de 2 a 3 minutos cl cambio dc color pueden ser evaluado visualmente o midiendo la absorbancia (ODE). Por adición de la solución Stopenzyme, por los niveles de aflatoxina en las muestras se pueden comparar con estándares coloreados (método cualitativo).

Las celdillas pueden ser leídas en un fotocolorimetro con filtro de $650 \mathrm{~nm}$ y los datos obtenidos se cuantifican usando el Logistic-log paper, un programa donde obtenemos la concentración de aflatoxinas en ppb (método cuantitativo).

\section{Contenido del Kit de ELISA}

- Cuatro tiras de 12 celdillas (48 celdillas) con anticuerpo fijados en su interior.

- Cuatro tiras de 12 celdillas (48 celdillas) marcado de rojo.

- Cuatro botellas con etiquetas amarillas de aflatoxinas control: 1,5 $\mathrm{mL}$ de $0,5,15,50 \mathrm{ppb}$ de aflatoxinas. Una botella con etiqueta azul de enzima - conjugado: $7 \mathrm{~mL}$ aflatoxina - HRP conjugado (Horseradish Peroxidase).

- Una botella con etiqueta verde de substrato: $24 \mathrm{~mL}$ de TMB (Tetrametilbenzidina). 
- Una botella de etiqueta roja de Stopenzime $32 \mathrm{~mL}$ de solución $(3,5 \mathrm{~mL}$ $\mathrm{HF}, 10,5 \mathrm{~g}$ sodio citrato, $6 \mathrm{~mL}$ de $\mathrm{NaOH} 1 \mathrm{~N}$ y $400 \mathrm{mg}$ edetato de sodio).

Los reactivos de deben de mantener a temperatura de refrigeración.

\section{Extracción de las muestras}

Las muestras se molieron hasta obtener partículas como café instantáneo; se mezclaron $5 \mathrm{~g}$ de muestra sólida como $25 \mathrm{~mL}$ de metanol al $70 \%$ agitando vigorosamente por 3 minutos, se filtro a través del papel Whatman $\mathrm{N}^{\mathrm{a}} 1$ y se trabajo con la solución filtrada.

\section{Procedimientos de la prueba de ELISA}

- Separar las celdillas de la mezcla (marcadas de rojo) de acuerdo a la cantidad de muestras a trabajar y 4 celdillas para los controles.

- De igual forma separar las celdillas fijadas con anticuerpos.

- Agitar los reactivos antes de ser usados y dejarlos a temperatura ambicntc.

- Llevar $100 \mathrm{uL}$ el de enzima conjugado (etiquetid azul) a cada celdillas de mezcla.

- Usar nuevos tips y transferir $100 \mathrm{uL}$ de controles $y$ muestras a las celdillas y mezclar con el conjugado dentro de ellas.

051550 M1 M2 M3 M4 M5 M6 M7

M8 tira 1

M9 M10 M11 M12 M13 14 M15 M16

M17 M18 M19 M20 tira 2

- Usar la pipeta multicanal (2 tips) y transferir 100 anticuerpos, mezclar e incubar por 2 minutos a temperatura ambiente.

- Descartar la mezcla de las celdillas, lavar 5 veces con agua desionizada, voltear las celdillas y secar en papel toalla.

- Transferir cantidad necesidad de enzima - substrato (etiqueta verde) a un envase largo o "bote para reactivos" y llevar a las celdillas $100 \mathrm{uL}$ de substrato usando una pipeta multicanal, mezclar completamente.

- Secar la parte inferior de las celdillas y leer en el fotocolorimetro EIA (NEOGEN) usando filtro de $650 \mathrm{~nm}$ (leer primero los controlcs, después las muestras).

\section{Resultados y discusión}

\section{Recuento de Hongos Aflatoxigénicos}

Los resultados en el recuento de hongos aflatoxigćnicos se observan en las tablas 2 y 3 .

En la tabla 2 se observa que el mayor número en el recuento de hongos aflatoxigenicos se encuentran en la muestra 4, soya alimentos naturales "la salud" con $3 \times 10^{2}$ ufc/g seguido de la muestra 3 y 6 kiwicha molida "productos andinos" y maca "Huayre", respectivamente con $2 \times 10^{2} \mathrm{ufc} / \mathrm{g} ; 21$ muestras tienen $<100 \mathrm{ufc/g}$. También se observan en la columna de nivel de aflatoxinas, que las mayores concentraciones se encuentran en la muestra 6, maca "Huayre" con $20 \mathrm{ppb}$, seguida de la muestra 9, Germen de trigo "Bircher Berber" con 16,5 ppb; las muestras 15 y 18 , galletas naturales dietéticas "productos vera" y kiwicha tostada y molida "Conselva", respectivamente tienen $0,0 \mathrm{ppb}$ de aflatoxinas.

Observamos en la tabla 3, que la mayor concentración de aflatoxina se encuentra en la muestra 36, Ginseng Dicter's Tea "King" con 103,7 ppb seguida de la muestra 28, Hercampuri "los ficus" con $81,4 \mathrm{ppb}$, la menor concentración de aflatoxina se encuentra en la mucstra 50, Conferí "ITEPAR" cápsulas con 2,6 ppb.

En la tabla 4 se observan que el promedio (mediana) de aflatoxina en los suplementos alimentarios es igual a 
$7,10 \mathrm{ppb}, \mathrm{y}$ en los medicamentos vegetales es igual a $41,90 \mathrm{ppb}$.

Al adquirir las muestras en establecimientos de venta de productos naturales se analizaron inicialmente su forma de presentación, donde se observó que los suplementos alimentarios 17 muestra se presentaban en bolsas simples y 9 muestras en bolsas dobles; por su parte, los medicamentos vegetales se encontraron 15 muestras en bolsa simple, 5 muestras en sobres filtrantes, 2 muestras en forma de cápsulas, 1 muestra en sobre y una muestra a grancl. Posteriormente, se determino el $\mathrm{pH}$ y la humedad de todas las muestras si son productos lábiles de ser contaminados por hongos productos de aflatoxina, quienes demostraron la relación existente entre $\mathrm{pH}$ y humedad con presencia de aflatoxinas en muestra de maíz y trigo. $\mathrm{El} \mathrm{pH}$ promedio de las muestras fue 5,54 y la unidad promedio 8,841 , estos resultados se encontraron dentro de las condiciones optimas para la producción de aflatoxinas Lie y Marth (referido en Ellis y Etal, 1991), reportaron que A. Flavus y $\mathrm{A}$. Parasiticus son capaces de crecer en un rango de $\mathrm{pH}$ que van de 1,7 a 9,34 con crecimiento optimo entre $\mathrm{pH} 3,42$ y 5,47. en el análisis estadístico, sc encontró diferencias significativas entre los promedios de los 2 grupos de muestras analizadas, los medicamentos vegetales presentaron $\mathrm{pH} 5,042$ y humedad 11,140, mientras que los suplementos presentaron $\mathrm{pH} 6 \mathrm{y}$ humedad 6,718 .

Los resultados obtenidos en los recuentos de hongos totales fueron transformados a logaritmo en base 10 ya que el fenómeno de los hongos no tienen distribución normal, sino distribución geométrica (ISO 1980) se utilizaron 2 medios de cultivo: Agar Sabouraud Oxitetraciclina (ASO) por ser el medio de cultivo mas común para ef recuento de hongos, y Agar Coco
Oxitetraciclina (CAMO) que es un medio para observar la fluorescencia de los hongos Aflatoxigenicos bajo la luz UV. En total, 42 muestras $(84 \%)$ se encontraron contaminadas siendo $12 \times 10^{3} \mathrm{ufc} / \mathrm{g}$ el valor mas alto en el recuento de hongos totales en los 2 medios de cultivo. Según el análisis estadístico (prueba " $t$ " de student) los medicamentos vegetales tuvieron como promedio en el recuento de hongos totales mas altos que los suplementos alimentarios en los dos medios de cultivo; estadísticamente se determino que no hay diferencias significativas en los recuentos de hongos por lo tanto, sc pueden utilizar cualquiera de los medios de cultivo para el recuento de hongos totales. Esos resultado coinciden con el trabajo realizado por Torres, donde analizó muestra de harina y alimentos para animales en 4 medios de cultivo, también demostró que el medio Agar Coco Oxitetraciclina (CAMO) es un método fácil y económico para detectar hongos aflatoxigenicos.

En el recuento de hongos aflatoxigénicos en Agar Coco Oxitetraciclina (CAMO) los resultados también se expresaron como logaritmos en base 10 . en total, 16 muestras (32\%) cstuvicron contaminadas con hongos productores de aflatoxinas. Según el análisis estadístico en el recuento de hongos aflatoxigénicos existió diferencias significativas entre los medicamentos vegetales y los suplementos alimentarios, el 1 grupo tuvo un promedio de 2,66 (antilog $5 \times 10^{2} \mathrm{ufc} / \mathrm{g}$ ) y 13 muestras presentaron $<100 \mathrm{ufc} / \mathrm{g}$, mientras que el 2 grupo tuvo un promedio de 2,21 (antilog $2 \times 10^{2} \mathrm{ufc} / \mathrm{g}$ ) y 21 muestras presentaron $<100 \mathrm{ufc} / \mathrm{g}$; estos resultados nos indican mayor contaminación de hongos aflatoxigénicos en muestra de medicamentos vegetales. 
Tabla 2

\section{RECUENTO DE HONGOS AFLATOXIGÉNICOS EN SUPLEMENTOS ALIMENTARIOS}

\begin{tabular}{|c|c|c|c|}
\hline MUESTRA & PRODUCTO & Uffc/g & $\begin{array}{c}\text { NIVEL DE } \\
\text { AFLATOXINA ppb }\end{array}$ \\
\hline 1 & Salvadn "Alimentos Naturales" & $<100$ & 16,0 \\
\hline 2 & Salvado de Trigo "Bircher Bemer" & $<100$ & 9,8 \\
\hline 3 & Kiwicha molida "Productos Andinos" & $2 \times 10^{2}$ & 8,3 \\
\hline 4 & Soya Alimentos Naturales "La Salud" & $3 \times 10^{2}$ & 9.7 \\
\hline 5 & Salvado de Trigo "Agroindustrial la Salud" & $<100$ & 4.4 \\
\hline 6 & Maca "Huayre" & $2 \times 10^{2}$ & 20 \\
\hline 7 & Kiwicha pop "Alimentos Andinos para Exportación" & $<100$ & 1,0 \\
\hline 8 & Kiwicha pop "Productos Andinos" & $<100$ & 4,7 \\
\hline 9 & Germen de Trigo "Bircher Berner" & $<100$ & 16,5 \\
\hline 10 & Soya cruda y molida "Nutri Andina" & $<100$ & 4,5 \\
\hline 11 & Kiwicha pop dulce "Covinda" & $<100$ & 2,4 \\
\hline 12 & Salvado de Trigo "Nutri Andina" & $<100$ & 7,1 \\
\hline 13 & Kiwicha pop "Nutri Andina" & $<100$ & 3,8 \\
\hline 14 & Trigo Atómicn "Productos TAJ" & $<100$ & 11,8 \\
\hline 15 & Galletas naturales dietéticas "Productos Vera" & $<100$ & 0,0 \\
\hline 16 & Carne de Soya "Bircher Bemer" & $<100$ & 10,9 \\
\hline 17 & Maca Vit "Productos Nuestra Seffora de Fátima" & $10^{2}$ & 11,4 \\
\hline 18 & Kiwicha tostada y molida "Conselva" & $<100$ & 0,0 \\
\hline 19 & Salvado de Trigo "Cogomo" & $<100$ & 4,4 \\
\hline 20 & Salvado de Trigo "Proina" & $<100$ & 5.2 \\
\hline 21 & Kiwicha dulce "For Export" & $<100$ & 10,9 \\
\hline 22 & Kiwicha tostada instantánea "Pruductos Valentina" & $10^{2}$ & 2,4 \\
\hline 23 & Germen de Trigo "Mi Salud" & $<100$ & 10,0 \\
\hline 24 & Quinua Tostadita "Conselva" & $<100$ & 3,6 \\
\hline 25 & Germen de Trigo "L'nión" & $\leq 100$ & 13,1 \\
\hline 26 & Kiwicha molida "Mi Salud" & $<100$ & No se analizo \\
\hline
\end{tabular}

Tabla 3

\section{RECUENTO DE HONGOS AFLATOXIGÈNICOS EN MEDICAMENTOS VEGETALES}

\begin{tabular}{|c|c|c|c|}
\hline MUESTRA & PRODUCTO & Ufc/g & $\begin{array}{c}\text { NIVEL DE } \\
\text { AFLATOXINAS pph }\end{array}$ \\
\hline 27 & Uña de Gato "Codeplan" S. R. Lida & $10^{2}$ & 63,5 \\
\hline 28 & Hercampuri "Los Ficus" & $4 \times 10^{2}$ & 81,4 \\
\hline 29 & Chance Piedra "Los Ficus" & $2 \times 10^{3}$ & 78,1 \\
\hline 30 & Hoja de Boldo "Los Ficus" & $<100$ & 30,6 \\
\hline 31 & Achiote & $5 \times 10^{2}$ & 29,4 \\
\hline$\overline{32}$ & Infusiones "Wawasana" & $13 \times 10^{2}$ & 48,2 \\
\hline 33 & Uña de Gato "Longfile" & $<100$ & No se analizo \\
\hline 34 & Uña de Gato "Medisana" & $3 \times 10^{2}$ & 24,8 \\
\hline 35 & Emoliente clásico "Medisana" & 102 & 17,5 \\
\hline 36 & Ginseng Dieter's tea "King" & $<100$ & 103,7 \\
\hline 37 & Higasan "Naturista Odilia" & $<100$ & No se analizo \\
\hline 38 & Valeriana "Los Ficus" & $10^{2}$ & 15,1 \\
\hline 39 & Bronquiosan "Naturista Odilia" & $<100$ & No se analizo \\
\hline 40 & Diabetisan "Naturista Odilia" & $4 \times 10^{2}$ & 41,9 \\
\hline 41 & Chuchuhuasi "Los Ficus" & $17 \times 10^{2}$ & No se analizo \\
\hline 42 & Uña de Gato "Los Ficus" & $<100$ & 23,7 \\
\hline 43 & Tonillo "Los Ficus" & $<100$ & 52,3 \\
\hline 44 & Rifosan "Odilia" & $2 \times 10^{3}$ & 59,6 \\
\hline 45 & Nerviosan "Naturista Odilia" & $<100$ & No se analizo \\
\hline 46 & Hoja de Tilo "Los Ficus" & $<100$ & No se analizo \\
\hline 47 & Te de zanahoria "Jelisa" & $<100$ & 44,1 \\
\hline 48 & Kore Ginseng Tea Korean & $<100$ & No se analizo \\
\hline 49 & Diente de León "ITEPAR" & $<100$ & 36,6 \\
\hline 50 & Conferí "ITEPAR" & $<100$ & 2.6 \\
\hline
\end{tabular}




\section{Tabla 4}

\section{RESUMEN DE DATOS DESCRIPTIVOS DE LA CUANTIFICACIÓN DE AFLATOXINAS FY ELISA TANTO EN SUPLEMENTOS ALIMENTARIOS Y MEDICAMENTOS VEGETALES}

\begin{tabular}{|c|c|c|c|}
\hline VARIABLE & MEDLANA & CUARTIL 1 & CUARTI 2 \\
\hline SUPLEMENTOS ALIMENTARIOS & 7,10 & 3,70 & 11,15 \\
\hline MEDICAMENTOS VEGETALES & 41,90 & 24,25 & 61,35 \\
\hline TOTAL & 11,60 & 4,47 & 31,35 \\
\hline
\end{tabular}

En la utilización de inductores para aumentar la producción de aflatoxinas se utilizaron 5 medios de cultivo y se observó en todos la fluorescencia de las aflatoxinas bajo la luz UV pero en el medio CAMO con todos los inductores (ion sn, extracto de levadura y sacarosa) se mas grande la fluorescencia.

Después de aislar los hongos aflatoxigenicos envíales (frascos pequeños) se procedió a su identificación usando microcultivos para su observación en el microscopio los difícilmente reconocibles se sembraron en Agar Czapeck extracto de levadura (Pitt, 1996), quien utilizo este medio para observar la morfología dc las especies de los géneros Aspergillus y Penicillium. Se identificaron cuatro especies de hongos aflatoxigenicos en 16 muestras (5 de suplementos alimentarios y 11 medicamentos vcgctales), estos son: Aspergillus flavus, Aspergillussp, Aspergillus Níger y Penicillium sp, siendo el mas abundante A. flavus seguido de Penicillium sp y solo 2 colonias de A. níger y 4 colonias de Aspergillus sp. En 3 muestras se identificaron dos diferentes hongos productores de aflatoxinas, donde la pareja conformada por A. flavus y Penicillium sp es la mas abundantc.

El kit de ELISA que se uso en la presente investigación sirve para $\mathbf{4 8}$ pruebas y para cuantificar aflatoxinas $B_{1}, B_{2}, G_{1}$ y $G_{2}$; el limite mas bajo detección en $1 \mathrm{ppb}$ (ug/ $\mathrm{kg}$ ) se usaron 4 pruebas para los controles y se analizaron 42 muestras, de las cuales 25 muestras eran suplementos alimentarios y 17 medicamentos vegetales.
De las 42 muestras analizadas, $40 \mathrm{sc}$ encuentran contaminadas con aflatoxinas $(95,24 \%)$, solo 2 muestras tuvieron $0 \mathrm{ppb}$ (pertenecen a los suplementos alimentarios), se utilizo como promedio a la mediana. El promedio total fue $11,60 \mathrm{ppb}$, la menor concentración fue 1 ppb y la mayor concentración 103,4 ppb según el análisis estadístico (prueba no parametrica "U" de Mann Whitney), existicron diferencias significativas entre las concentraciones de suplementos alimentarios y los medicamentos vegetales, el 1 grupo tuvo un promedio dc $7,10 \mathrm{ppb}$ donde la menor concentración fue 1 ppb y la mayor concentración $20 \mathrm{ppb}$.

El 2 grupo tuvo un promedio de 41,9 ppb siendo la menor concentración 2,6 ppb y la mayor 103,4 ppb estos resultados nos indicaría que los medicamentos vegetales se encontraron concentraciones mas altas de aflatoxina. Por ultimo el limite máximo tolerable para los alimentos de consumo humano en el Perú es de 10 ppb según el codees alimentario (referido por Torres) pues no hay normas alimentarías en nuestro país. De acuerdo a este parámetro se tuvo que 17 mucstras $(40,5 \%)$ están por debajo de 10 ppb y 25 muestras $(59,55)$ por encima. En los suplementos alimentarios 16 muestra (64\%) estuvieron por debajo de 10 ppb y 9 muestras $(36 \%)$ por encima 1 , en los medicamentos vegetales una muestra $(5,9 \%)$ estuvo por debajo de $10 \mathrm{ppb}$ y 16 muestras $(94,1 \%)$ por encima. La administración de alimentos y drogas (FDA) establece quc cl limite máximo permitido en los alimentos y productos 
para consumo humano es de $20 \mathrm{ppb}$, según este parámetro 27 muestra $(64,3 \%)$ esta por debajo de $20 \mathrm{ppb}$ y 15 muestras $(35,7 \%)$ por encima. En suplementos alimentarios, 24 muestras (96\%) estuvieron por debajo de $20 \mathrm{ppb}$ y una muestra $(4 \%)$ por encima, en los medicamentos vegetales 3 muestras $(17,6 \%)$ están por debajo de 20 ppb y 14 muestras $(82,4 \%)$ por encima.
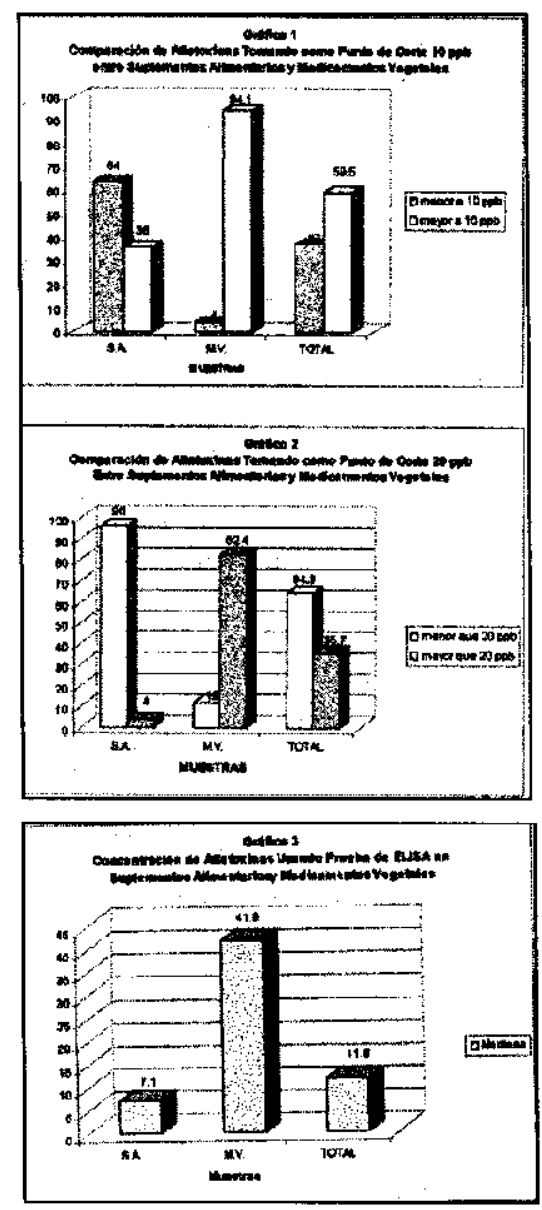

\section{Conclusiones y Recomendaciones}

La presente investigación tuvo las siguientes conclusiones:

1. El $84 \%$ de las muestras analizadas se encontraron contaminadas con hongos. En el recuento de hongos totales no hay diferencias entre el Agar Sabouraud Oxitctraciclina
(ASO) y Agar Coco Oxitetraciclina (CAMO) por lo tanto únicamente se puede usar CAMO para los recuentos de hongos totales $y$ hongos aflatoxigénicos.

2. El $32 \%$ de las muestras analizadas estuvieron contaminadas con hongos aflatoxigénicos. El Agar Coco Oxitetraciclina (CAMO), es un buen método preliminar para determinar la existencia de aflatoxina ya que es fácil y económico. Para observar la mayor producción de aflatoxina se puede usar CAMO mas de tres inductores (ion zinc, extracto de levadura y sacarosa).

3. El $95,2 \%$ de las muestras analizadas se encontraron contaminadas con aflatoxinas, la carencia de hongos en. la mucstra no nccesariamente indica la ausencia de aflatoxinas. Las muestras contienen un promedio de $11,6 \mathrm{ppb}$ de aflatoxinas y en los medicamentos vegetales se encontró la mayor concentración de aflatoxinas por encima de $20 \mathrm{ppb}$ índice máximo tolerable segû̉n FDA.

4. El Agar Czapeck extracto de levadura es un magnifico medio de cultivo para la identificación de especies del genero Aspergillus.

Como resultante del presente trabajo de investigación, podemos recomendar lo siguiente:

1. Los reactivos del kit de ELISA deben ser utilizados a temperatura ambiente y usados antes de la fecha de expiración; en la prueba de elisa se debe respetar los tiempos de incubación.

2. El Ministerio de Salud debe estableccr normas para el análisis de aflatoxinas antes y después de la elaboración de todos los productos que van a ser consumidos.

3. Ampliar los estudios sobre el análisis de aflatoxinas en el carnes, 
vísceras $\mathrm{y}$ otros productos de consumo humano

\section{Referencias}

Aflatoxina. Mycotoxinas. 1997 (citada 24 de marzo de 1998). Home page:

http://orion.ufrgs.br/farmacia/megadado s/files/aflatoxins.

Aflatoxins. $1995 . \quad$ Neogen

Corporation. Miami. (citada el 30 de abril de 1998). Home page:

http://www.Neogen.com

Aflatoxins. Mycotoxins and mycotoxicosis. 1996 (citada 30 de abril de 1998). Home page:

http://www.botany.hawaii.edu/faculty/w ong7bot 135/lect 111.htm

Aflatoxins. Nabil Saad. 1997 (citada 30 de abril de 1998). Home page:

http://www.ansci.cornll.edu/toxicagents laflatoxin/image.

Agrios G. 1994. Mycotoxins. Fitopatología. (citada 30 de abril de 1998). Home page:

http:/www.healthanswers.com/database /ami/converted/002429.html

Andrews W. 1992. manual of Food Quality Control. Mycrobiological Analysis. Food and Agriculture Organization of the United Nations. 4 (Rev 1): 221-36. Roma.

El Kadi I, El Maraghy S, Zohri AN. 1994. Mycotoxins producing potencial of some isolates of A. Flavus and Eurotium groups from meat products. Microbiol-Res. Sep 149 (3):297-307.

Ellis WO, Smith JP, Simpson BK, Oldham JH. 1991. Aflatoxins ind food: Ocurrence, Biosynthesis, Effects on Organisms, Detection, and Methods of Control. Crit-Rev-Food-Sci-Nutr. 30 (3): 413-39.

Jacobsen BJ, Bowen KL, Shelby RA, Diener UL. 1993. Mycotoxin and Mycotoxicoses. Extensión Veterinarian. Auburn University. Alabama. Pp. 3-10
Mycotoxins. Tech Fash. 1997. Countrymark Cooperative. Texas. (citada el 30 de abril de 1998)Home page:http://www.maff.gov.uk/food/infs heet/1996/no78/78afla.htm.

Pelczar M, Reid RD, Chane C. 1990. Microbiología. 4ta Edición. Mc. Graw Hill. México D.F. pp. 247-250.

Pitt J. 1996. An Introduction to Penicillum and Aspergillus Identification. CSIRO Division of Food Science and Technology. North Ryde. Pp. 2-5.

Pitt J, 1996. Major Genera of Foodborne Fungi. CSIRO División of Food Science and Technology. North Ryde pp. 4-7.

Reyes E. 1982. Determinación de Aflotoxinas $M I$ en Productos Alimenticios de Origen Animal en Guatemala. XI Congreso Panamericano de Farmacia y Bioquímica Colegio Farmacéutico del Pcrú. Lima. Pp. 326332.

Ruan CC. 1991. The co-mutagenic effect of metabolic extracts of fungi grown on the main grain in high incidence liver cancer areas Fusui Country. Chung-Hua-Yu-Fang-IHsuch_Tsa-Chih. Sep 25 (85): 288

Shane SM. 1994. Mycoloxicoses. Shool of Veterinary Medicine. Louisiana State. Univcrsity. Lousiana. pp. 2-6.

Whitlow LW, Hagler WM. 1994. Micotoxinas. Poultry Science Department. North Carolina State University North Carolina. Pp. 2-6.

Wolushuk CP, Foutz KR, Brewer JF, Bratnagar D, Cleveland T, Payne GA. 1994. Molecular characterization of afIR a regulatory locus for aflatoxin biosynthesis. Jul 60(7): 2408-14.

Woloshuk CP. 1997. Mycotoxins and Mycotoxin Test Kits. Corn Diseases. Department of Botany and Plant Pathology. Purduc University. West Lafayette. IN. 1997. pp. 2-4. 